\title{
Relationship Between Serum Amyloid AI (SAAI) Gene Polymorphisms Studies with Obesity in the Saudi Population
}

\author{
Khalid Khalaf Alharbi \\ Amal F Alshammary \\ Omar Sammar Aljabri (D) \\ Imran Ali Khan (D) \\ Department of Clinical Laboratory \\ Sciences, College of Applied Medical \\ Sciences, King Saud University, Riyadh, \\ Saudi Arabia
}

This article was published in the following Dove Press journal: Diabetes, Metabolic Syndrome and Obesity: Targets and Therapy

Purpose: Limited studies have shown positive and negative associations of serum amylase A1 (SAA1) gene in childhood obesity, previously showed the relation with obesity in different ethnicity. The current study therefore investigated the impact of single nucleotide polymorphisms present in the $S A A 1$ gene on subjects of Saudi obesity.

Participants and Methods: In this case-control study, we selected 140 subjects of Saudi population and categorized them into 83 cases of obesity and 57 healthy controls. Genotyping was performed with quantitative/real time-polymerase chain reaction in the SAA1 gene for rs11603089A/G, rs4638289A/T and rs7131332A/G polymorphisms.

Results: In rs11603089 polymorphism, co-dominant model (AG vs AA+GG; OR-2.23 [95\% CI:1.02-4.86]; $\mathrm{p}=0.04$ ) and $\mathrm{rs} 4638289$ polymorphism, a disparity in significance was observed between the homozygous variant (TT vs AA; OR-16.8 [95\% CI: 2.06-136.8]; $\mathrm{p}=0.0009$ ), dominant model (AT+TT vs AA; OR-2.57 [95\% CI: 1.28-5.19]; p=0.007), recessive model (TT vs AA+AT; OR-11.36 [95\% CI: 1.45-89.06]; $\mathrm{p}=0.004$ ) and allelic frequency for ( $\mathrm{T}$ vs A: OR-2.35 [95\% CI: 1.39-3.98]; $\mathrm{p}=0.001$ ) between the obesity cases and control subjects. However, statistical correlations did not reveal the rs $7131332 \mathrm{~A} / \mathrm{G}$ polymorphism either $(\mathrm{p}>0.05)$.

Conclusion: In conclusion, rs4638289 polymorphism was associated with risk allele and dominant model with obesity subjects. Further additional studies were warranted.

Keywords: obesity, SAA1 gene, rs11603089, rs4638289 and rs7131332 polymorphisms

\section{Introduction}

Obesity (OMIM: 601,665) is reported as one of the inherited and multiple metabolic disorders in humans. ${ }^{1,2}$ Calmly, obesity represents a major health problem globally with 0.4 billion people affected. ${ }^{3}$ Visceral adipose tissue in human is more closely associated with metabolic disease than subcutaneous adipose tissue. ${ }^{4}$ The rate of obesity has almost tripled globally in the last decades, with an estimated 1.9 billion adults overweight. ${ }^{5}$ Although obesity has become a pandemic and a major burden in one of the high-income countries in Kingdom of Saudi Arabia. ${ }^{6}$ Body Mass Index (BMI) is widely used for diagnosing obesity. While BMI has an association with body fat mass that may be overestimated in people with high muscle mass. Similarly, BMI was revealed since not all obese people experience metabolic disorders commonly associated with obesity. ${ }^{7}$ With an enormous chronic metabolic disorder, involves insulin resistance, dyslipidemia, type 2 diabetes, obesity will progress and manifests the diseases associated with obesity

Correspondence: Imran Ali Khan Department of Clinical Laboratory Sciences, College of Applied Medical Sciences, King Saud University, PO Box10219, Riyadh, I1433, Kingdom of Saudi Arabia

Tel +96650 III 2806

Fax +966114693851

Email imkhan@ksu.edu.sa 
and will increase cardiovascular morbidity and mortality, which further leads towards heart failure, arrhythmia and sudden cardiac death. ${ }^{8}$

The relationship between observational, case-control, genetic linkage, candidate gene, and genome-wide association (GWAS) studies between candidate obesity genes and body weight-related obesity has been documented with nearly 600 genes, and chromosomal regions have been confirmed to participate in the regulation of BMI and energy metabolism. There are numerous genes associated with human obesity including serum amylase A1 (SAA1) with the role of obesity. ${ }^{9}$ Zhang et al ${ }^{10}$ reported the relationship between obesity and $S A A 1$ gene. Obsession also affects systemic inflammatory responses, including moderately elevated serum levels of the acute phase protein Amyloid A (SAA), which are suggested to contribute to the development of type 2 diabetes and tolerance to insulin. SAA has been studied in several ways, but its function is still quite unclear. SAA is an apolipoprotein and is mainly associated with circulating HDL particles. SAA is proposed to include processes such as cholesterol, lipolytic and opsonic transport and the production of pro-inflammatory cytokines. ${ }^{11}$ In addition to being a plasma sensitive phase protein, SAA is an apolipoprotein that can replace the main apolipoprotein HDL-C, apolipoprotein A1, especially in the acute phase reaction. ${ }^{10}$ For highly inducible acute phase SAA proteins in the acute phase response, SAA1 code. Human SAA1 is best recognized among all known SAA proteins for its physiologically sound and genepolymorphic functions. SAA1 encodes 122 pre-protein amino acids, including the 18-amino acid peptide signal. With just a few amino acids, the genetic materials of these coding alleles vary at positions 52, 57, 60 and $72 .^{12}$

The rs11603089, rs4638289 and rs7131332 polymorphisms or single nucleotide polymorphisms (SNPs) have a functional role without any protein effect. $S A A 1$ gene is acute-phase encoding in SAAs. Earlier reports in the effect of a $S A A 1$ gene polymorphism on SAA plasma concentration and another GWAS revealed that the $S A A 1$ gene polymorphism is substantially linked to an increase in SAA plasma. ${ }^{13}$ Limited genes were screened in the Saudi population with the obesity subjects. There were no studies have been implemented in the $S A A 1$ gene in the obesity subjects in the Saudi population. So, therefore present study was aimed to investigate the relationship between $S A A 1$ gene polymorphisms in the Saudi obese subjects.

\section{Participants and Methods Sample Selection}

This is a case-control study performed in the College of Applied Medical Sciences after obtaining the ethical grant within the college premises (CAMS054-3839). This study was conducted in accordance with the Declaration of Helsinki. In this study, we have recruited 83 obesity cases and 57 matching controls. The inclusion criteria of the obese subjects were based on body mass index (BMI $>30 \mathrm{~kg} / \mathrm{m}^{2}$ ) without other medical complications and for controls it will be Saudi subjects without obesity or nonBMI $\left(<25 \mathrm{~kg} / \mathrm{m}^{2}\right)$. The exclusion criteria of the obesity cases were low BMI, non-Saudi subjects and with other disease complications and in controls will be the nonSaudi subjects and obese patients with BMI $>30 \mathrm{~kg} / \mathrm{m}^{2}$. All the participants signed the informed consent form before participation in this study. Age, gender and BMI details as well as other medical complications were recorded in this study.

\section{Molecular Analysis}

Genomic DNA was extracted from EDTA blood using Genomic purification kit and NanoDrop ${ }^{\mathrm{TM}}$ spectrophotometer was performed to quantify the concentration of genomic DNA prior to performing the quantitative polymerase chain reaction (qPCR). Genotyping methodology was performed as per the Alharbi et $\mathrm{al}^{14}$ studies for rs11603089 [A/G], rs4638289 [A/T] and rs7131332 [A/ G] using VIC and FAM probes as described.

\section{Statistical Analysis}

Statistical analysis was performed as per Khan et al ${ }^{15}$ studies using the data analysis. Continuous variables were expressed as mean \pm standard deviation $(\mathrm{m} \pm \mathrm{SD})$ and categorical variables were expressed as percentages. A p value $<0.05$ was considered as statistically significant. Linkage Disequilibrium (LD) was performed with $\mathrm{R}$ software using three SNPs involved in this study.

\section{Results}

\section{Non-Genotypic Data Analysis}

In this case-control study, a total of 140 Saudi subjects were enrolled. Among them, 83 obesity cases and 57 control subjects were confirmed. Among 140 Saudi 
Table I Clinical Characteristics Between Obesity Cases and Healthy Controls

\begin{tabular}{|l|c|c|c|c|}
\hline S. No. & Baseline Characteristics & Obesity Cases (n=83) & Controls (n=57) & P-value \\
\hline I & Age (Years) & $30.4 \pm 6.4$ & $24.4 \pm 4.6$ & 0.00 I \\
2 & Gender (Male: Female) & $47(56.6 \%): 36(43.4 \%)$ & $32(56.1 \%): 25(43.9 \%)$ & 0.91 \\
3 & Weight (kgs) & $80.4 \pm 18.1$ & $55.07 \pm 7.28$ & $<0.00$ I \\
4 & Height (cms) & $160.7 \pm 8.51$ & $162.1 \pm 7.1$ & 0.30 \\
5 & BMI (kg/m $\left.\mathrm{m}^{2}\right)$ & $30.9 \pm 5.61$ & $0.89 \pm 1.86$ & 1.0 \\
6 & Family History of Metabolic diseases & $0(0 \%)$ & $0(0 \%)$ & 1.0 \\
7 & Family History of Cardiac diseases & $0(0 \%)$ & & \\
\hline
\end{tabular}

subjects, $44 \%$ were females and $56 \%$ were males. Table 1 describes the anthropometric characteristics and related family histories of the involved Saudi subjects. All the involved participants' mean age was found to be 30.4 \pm 6.4 in obesity cases and $24.4 \pm 4.6$ in the control subjects, which was found to statistically significant $(\mathrm{p}=0.001)$. Gender $(\mathrm{p}=0.91)$ and height $(\mathrm{p}=0.30)$ was found to be nonsignificant association $(\mathrm{p}>0.05)$. Both the weight and BMI were found to be statistically significant $(p<0.001)$. However, all the participants were free of family histories for both the metabolic and cardiac diseases $(p=1.0)$.

\section{HWE Analysis}

The HWE was calculated and confirmed the genotype distribution with control subjects only in rs7131332 $\left(\chi^{2}=0.35\right.$; $\mathrm{p}=0.55)$; whereas in both $\mathrm{rs} 11603089\left(\chi^{2}=4.22 ; \mathrm{p}=0.03\right)$ and rs463829 $\left(\chi^{2}=3.03 ; \mathrm{p}=0.08\right)$. The details were shown in Table 2.

\section{Genotype Analysis}

Table 3 describes genotype and allele frequencies between obesity cases and controls. Genotyping was performed for rs11603089, rs4638289 and rs7131332 SNPs between the obesity cases and controls. The rs7131332 SNPs did not show any significant associations between genotypes, dominant model and allele frequencies between cases and controls (rs7131332; AG+GG- [OR: 1.08 (0.55-2.13); $\mathrm{p}=0.80]$, AG vs AA- [OR-0.84 (0.41-1.70); $\mathrm{p}=0.63]$ and $\mathrm{G}$ vs A- [OR-0.75 (0.45-1.25); $\mathrm{p}=0.27]$. However, rs11603089 polymorphism showed association only with co-dominant model ie, AG vs AG+GG- [OR: 2.23 (1.024.86); $\mathrm{p}=0.04]$, and for rs4638289 SNP was found to be statistically significant in dominant mode [OR-2.57 (1.28-5.19); $\mathrm{p}=0.007$ ], recessive model [OR-11.36 (1.4589.06); $\mathrm{p}=0.004]$, TT vs AA [OR-16.8 (2.06-136.8); $\mathrm{p}=0.0009]$ and allele mode of frequencies ( $\mathrm{T}$ vs A- [OR2.35 (1.39-3.98); $\mathrm{p}=0.001]$ ).

\section{Linkage Disequilibrium Analysis}

Delta Coefficient $\left(\mathrm{D}^{\prime}\right)$ specified LD analysis was calculated in the $S A A 1$ gene both for patients and controls for the three SNPs (rs11603089, rs4638289, and rs7131332). No similarity between the three SNPs was found (Figure 1; Table 4).

\section{Discussion}

The aim of the present study was to assess the relationship between SAAl gene polymorphisms in the Saudi obese subjects. No significant association was found with the studies three SNPs (rs11603089, rs4638289 and rs7131332) used in this study with obesity, however rs4638289 polymorphism in the SAAl gene was correlated with the possibility of obese but not with the prospect of overweight in the dominant mode of inheritance $(p=0.007)$ as well as allelic frequencies $(p=0.001)$. Our study is in agreement with the findings of other global studies on obesity. ${ }^{10}$ The results of our study are almost in accordance with the Zhang et $\mathrm{al}^{8}$ studies with polymorphisms rs11603089 and rs4638289, but not with the polymorphism rs7131332. The genotype frequencies for AA,

Table 2 Hardy Weinberg Equilibrium Analysis

\begin{tabular}{|l|l|l|l|l|l|}
\hline S.No & Gene & rs Number & $\chi^{2}$ & P-value & HWE Criteria \\
\hline$I$ & SAAI & rsII603089 & 4.22 & 0.03 & Non-HWE criteria \\
2 & SAAI & rs4638289 & 3.03 & 0.08 & Non- HWE criteria \\
3 & SAAI & rs7I3I332 & 0.35 & 0.55 & HWE criteria \\
\hline
\end{tabular}


Table 3 Genotype and Allele Frequencies in rs I 1603089, rs4638289 and rs7I31332 Polymorphisms in SAAI Gene in Obesity Cases and Control Subjects

\begin{tabular}{|c|c|c|c|c|c|c|}
\hline SNPs & $\begin{array}{c}\text { Genotypes/ } \\
\text { Alleles }\end{array}$ & Cases $(n=83)$ & Controls $(n=57)$ & Odds Ratio & $95 \% \mathrm{Cl}$ & P-value \\
\hline \multirow[t]{8}{*}{ rs II603089 } & $\mathrm{AA}$ & $49(59.0)$ & $4 I(71.9)$ & Reference & Reference & Reference \\
\hline & AG & $31(37.3)$ & $12(21.1)$ & 2.16 & $0.98-4.73$ & 0.05 \\
\hline & GG & $3(3.6)$ & $4(7.0)$ & 0.62 & $0.13-2.96$ & 0.66 \\
\hline & $A G+G G$ vs $A A$ & $34(40.9)$ & $16(28.1)$ & 1.77 & $0.86-3.67$ & 0.11 \\
\hline & $A G$ vs $A A+G G$ & $31(37.3)$ & $12(21.1)$ & 2.23 & $1.02-4.86$ & 0.04 \\
\hline & $G G$ vs $A A+A G$ & $3(3.6)$ & $4(7.0)$ & 0.49 & $0.10-2.31$ & 0.36 \\
\hline & A & $129(77.7)$ & $94(82.5)$ & Reference & Reference & Reference \\
\hline & G & $37(22.3)$ & $20(17.5)$ & 1.34 & $0.73-2.47$ & 0.33 \\
\hline \multirow[t]{8}{*}{ rs4638289 } & $\mathrm{AA}$ & $25(30.1)$ & $30(52.6)$ & Reference & Reference & Reference \\
\hline & AT & $44(53.0)$ & $26(45.6)$ & 2.03 & $0.98-4.16$ & 0.05 \\
\hline & $\mathrm{TT}$ & $14(16.9)$ & I (I.8) & 16.8 & $2.06-136.8$ & 0.0009 \\
\hline & $\mathrm{AT}+\mathrm{TT}$ vs $\mathrm{AA}$ & $58(69.9)$ & $27(47.4)$ & 2.57 & $1.28-5.19$ & 0.007 \\
\hline & AT vs $\mathrm{AA}+\mathrm{TT}$ & $44(53.0)$ & $26(45.6)$ & 1.34 & $0.68-2.64$ & 0.38 \\
\hline & TT vs $A A+A T$ & $14(16.9)$ & I (I.8) & 11.36 & $1.45-89.06$ & 0.004 \\
\hline & A & $94(56.6)$ & $86(75.4)$ & Reference & Reference & Reference \\
\hline & $\mathrm{T}$ & $72(43.4)$ & $28(24.6)$ & 2.35 & 1.39-3.97 & 0.001 \\
\hline \multirow[t]{8}{*}{ rs7/31332 } & $\mathrm{AA}$ & $39(47.0)$ & $23(40.4)$ & Reference & Reference & Reference \\
\hline & AG & $40(48.2)$ & $28(49.1)$ & 0.84 & $0.4 I-1.70$ & 0.63 \\
\hline & GG & $4(4.8)$ & $6(10.5)$ & 0.39 & $0.10-1.54$ & 0.17 \\
\hline & $A G+G G$ vs $A A$ & $44(53.0)$ & $29(50.9)$ & 1.08 & $0.55-2.13$ & 0.80 \\
\hline & $A G$ vs $A A+G G$ & $40(48.2)$ & $28(49.1)$ & 0.96 & $0.49-1.89$ & 0.91 \\
\hline & $G G$ vs $A A+A G$ & $4(4.8)$ & $6(10.5)$ & 0.43 & $0.11-1.60$ & 0.19 \\
\hline & A & II8 (7I.I) & $74(64.9)$ & Reference & Reference & Reference \\
\hline & $\mathrm{G}$ & $48(28.9)$ & $40(35.1)$ & 0.75 & $0.45-1.25$ & 0.27 \\
\hline
\end{tabular}

$\mathrm{AG}$ and $\mathrm{GG}$ were found to be $68 \%, 28 \%$ and $4 \%$ in rs11603089 SNP and were reported to be 59\%, 37.3\% and $3.6 \%$ respectively in our study. With $33 \%$ in AA, $44 \%$ in AT and $23 \%$ in TT genotypes, the 2nd SNP (rs4638289) was reported; whereas in our study, it was reported to be $30.1 \%, 53 \%$ and $16.9 \%$ respectively. The AA, AG and GG genotypes were found to be $24 \%, 58 \%$ and $18 \%$ with the rs7131332 polymorphism, and our findings were stated to be $47 \%, 48.2 \%$ and $4.8 \%$, respectively.

The polymorphisms rs11603089, rs4638289 and rs7131332 in the SAA1 gene were studied in Kawasaki disease subjects with limited ethnicity. ${ }^{10,16}$ The Ying et al ${ }^{13}$ studies were conducted with rs4638289 and rs7131332 polymorphisms in Kawasaki disease. With our current study findings, the genotype frequencies in the case subjects were almost identical. The disease differs, however, from the studies of Ying et $\mathrm{al}^{13}$ In addition to obesity, the additional SNPs in $S A A 1$ gene were used in other diseases in global populations. ${ }^{17,18}$ In Chinese women diagnosed with Osteoporosis in rs12218 polymorphism, Feng et $\mathrm{al}^{14}$ studies were conducted and this polymorphism was not performed to compare genotype findings in our current research. Yashiro et $\mathrm{al}^{15}$ studies were conducted in adult onset still disease with rs1136743 and rs1136747 polymorphisms with $S A A 1$ gene and these related polymorphisms were not conducted in this current study. None of the meta-analysis studies of obesity and SAAI gene polymorphism were conducted in the global population. This may be due to the limited case-control studies performed in the different ethnicities. However, Zhao et al ${ }^{19}$ performed a meta-analysis study focused only on BMI and SAA levels with various global studies but not with the genotyping analysis.

Obesity is considered to be an inherited disorder that is related to both genetic and non-genetic ie, environmental factors may play an important role. Genetic factors play an important role in obesity, particularly when regulating weights. $^{20}$ Obesity is strongly associated with Saudi Arabia because of various factors. The prevalence of 


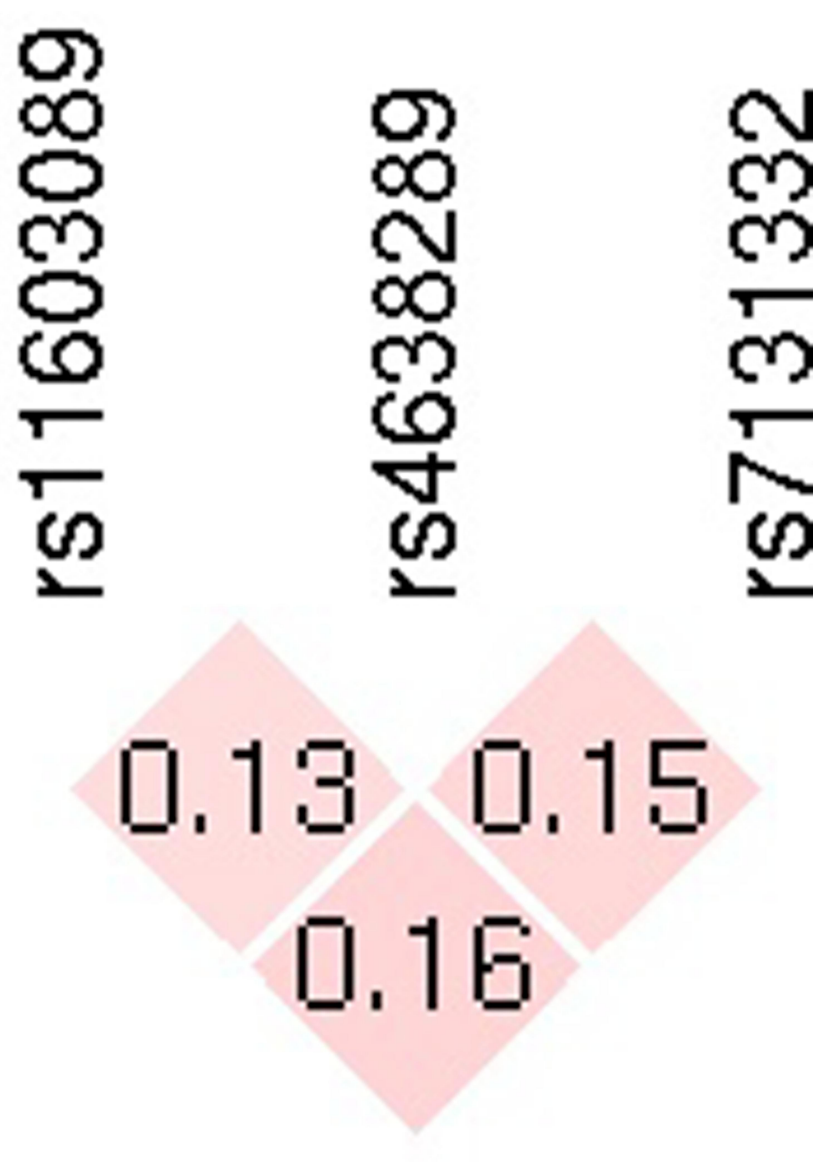

Figure I Linkage disequilibrium continuum of the genomic region in chromosome II position between 3 SNPs (rsII603089, rs4638289, and rs7I3I332) in SAAI gene.

obesity was confirmed at $52.9 \%$ in 2017 and $59.5 \%$ was expected to rise in $2022 .{ }^{6}$ The genetic influence on obesity may be due to the involvement of multiple SNPs linked to obesity and its associated phenotypes. There are multiple gene polymorphisms, observational, and numerous studies of obesity in the different regions of the Saudi Arabia have been carried out. SAA1 was originally described as an antisera-recognized serum component against amyloid fibrils, known as AA. Subsequently, it was found that SAA1 acts as a major precursor of AA and is an HDL apolipoprotein in the acute-phase serum. The human

Table 4 Linkage Disequilibrium Analysis with SNPs Involved in This Study

\begin{tabular}{|l|c|c|c|}
\hline & rs11603089 & rs4638289 & rs7131332 \\
\hline rs11603089 & I & 0.132 & 0.16 \\
rs4638289 & 0.132 & I & 0.154 \\
rs7131332 & 0.16 & 0.154 & I \\
\hline
\end{tabular}

SAA1 is best characterized by its physiological roles and gene polymorphisms between all known SAA proteins. Human SAA1 is located in the chromosome 11 short arm and comprises 4 exons with exon 2-4 coding sequences, respectively. ${ }^{12}$ The current studies' strength was to optimize Saudi subjects, opt for three SNPs and performed qPCR. One of the study's major limitations was the limited sample size. Missing the enrolled biochemical data was one of the limitations of this study.

\section{Conclusion}

The present study concludes that $S A A 1$ gene was associated with rs11603089, rs4638289 polymorphisms in the Saudi obese population. Future research to carry out the meta-analysis studies should be carried out in other ethnicities.

\section{Abbreviations}

SAA1, serum amyloid A1; BMI, body mass index; qPCR, quantitative polymerase chain reaction; GWAS, genomewide association studies, HDL, high-density lipoprotein.

\section{Data Sharing Statement}

The data analyzed during the current study are available from the corresponding author on reasonable request.

\section{Ethics Statement}

This study was approved by the Institutional Review Board (IRB) of College of Applied Medical Sciences at King Saud University (approval No. CAMS054-3839). All participants provided written informed consent, and ethics approval was obtained from the IRB of each participating institute.

\section{Acknowledgment}

The authors would like to extend their sincere appreciation to the Deanship of Scientific Research at King Saud University for its funding of this research through the Research Group Project No. RGP-244.

\section{Author Contributions}

All authors made a significant contribution to the work reported, whether that is in the conception, study design, execution, acquisition of data, analysis and interpretation, or in all these areas; took part in drafting, revising or critically reviewing the article; gave final approval of the version to be published; have agreed on the journal to which the article has been submitted; and agree to be accountable for all aspects of the work. 


\section{Disclosure}

The authors report no conflicts of interest in this work.

\section{References}

1. Rodgers GP, Gibbons GHJJ. Obesity and hypertension in the time of COVID-19. JAMA. 2020;324(12):1163-1165. doi:10.1001/jama.20 20.16753

2. Yu S, Li X, Yu F, et al. New evidence for associations between vitamin D receptor polymorphism and obesity: case-control and family-based studies. J Hum Genet. 2020;65(3):281-285. doi:10. 1038/s10038-019-0702-5

3. Wei B-L, Yin R-X, Liu C-X, Deng G-X, Guan Y-Z, Zheng P-FJMM. The MC4R SNPs, their haplotypes and gene-environment interactions on the risk of obesity. Mol Med. 2020;26(1):1-10. doi:10.1186/ s10020-020-00202-1

4. Strieder-Barboza C, Baker NA, Flesher CG, et al. Depot-specific adipocyte-extracellular matrix metabolic crosstalk in murine obesity. Adipocyte. 2020;9(1):189-196. doi:10.1080/21623945.2020.1749500

5. Mylona EK, Benitez G, Shehadeh F, et al. The association of obesity with health insurance coverage and demographic characteristics: a statewide cross-sectional study. Medicine. 2020;99(27):e21016. doi:10.1097/MD.0000000000021016

6. Alqarni SSM. A review of prevalence of obesity in Saudi Arabia. Obesity Eat Disord. 2016;2(2):25.

7. Kim B-R, Seo JW, Kim SM, Kim K-N, Joo N-M. The presence of urinary ketones according to metabolic status and obesity. $J$ Korean Med Sci. 2020;35:31.

8. Chen H, Wang X, Xiong C, Zou H. Nanomedicine, biotechnology. The negative effects of obesity on heart, especially the electrophysiology of the heart. Artif Cells, Nanomed Biotechnol. 2020;48 (1):1055-1062. doi:10.1080/21691401.2020.1770269

9. Deram S, Villares SMF. Genetic variants influencing effectiveness of weight loss strategies. Arq Bras Endocrinol Metabol. 2009;53 (2):129-138. doi:10.1590/S0004-27302009000200003

10. Zhang X, Tang QZ, Wan AY, Zhang HJ, Wei L. SAA1 gene variants and childhood obesity in China. Lipids Health Dis. 2013;12(1):1-4. doi:10.1186/1476-511X-12-161
11. Ahlin S, Olsson M, Olsson B, Svensson PA, Sjöholm K. No evidence for a role of adipose tissue-derived serum amyloid a in the development of insulin resistance or obesity-related inflammation in hsaal +/- transgenic mice. PLoS One. 2013;8(8):e72204. doi:10.1371/journal.pone.0072204

12. Sun L, Ye RD. Serum amyloid A1: structure, function and gene polymorphism. Gene. 2016;583(1):48-57. doi:10.1016/j.gene.2016. 02.044

13. Xie X, Ma YT, Yang YN, et al. Genetic polymorphisms of serum amyloid A1 and coronary artery disease risk. Tissue Antigens. 2015;85(3):168-176. doi:10.1111/tan. 12516

14. Alharbi KK, Al-Sulaiman AM, Bin Shedaid MK, et al. MTNR1B genetic polymorphisms as risk factors for gestational diabetes mellitus: a case-control study in a single tertiary care center. Ann Saudi Med. 2019;39(5):309-318. doi:10.5144/0256-4947.2019.309

15. Khan IA, Jahan P, Hasan Q, Rao P. Genetic confirmation of T2DM meta-analysis variants studied in gestational diabetes mellitus in an Indian population. Diabetes Metab Syndr. 2019;13(1):688-694. doi:10.1016/j.dsx.2018.11.035

16. Chen Y, Cheng W, Ji Q, Zhang J, Cheng T, Wang S, Yi X. Study on the correlation between SAA1 gene rs4638289 and rs7131332 polymorphisms and Kawasaki disease. Zhongguo Dang Dai Er Ke Za Zhi. 2020;22(6):614-619. doi:10.7499/j.issn.1008-8830.1912093

17. Feng ZP, Li XY, Jiang R, et al. Associations of SAA1 gene polymorphism with lipid levels and osteoporosis in Chinese women. Lipids Health Dis. 2013;12(1):39. doi:10.1186/1476-511X-12-39

18. Yashiro M, Furukawa H, Asano T, et al. Serum amyloid A1 (SAA1) gene polymorphisms in Japanese patients with adult-onset Still's disease. Medicine. 2018;97(49):e13394. doi:10.1097/MD.00000000 00013394

19. Zhao Y, He X, Shi X, et al. Association between serum amyloid A and obesity: a meta-analysis and systematic review. Inflamm Res. 2010;59(5):323-334. doi:10.1007/s00011-010-0163-y

20. Sorensen TIA, Boutin P, Taylor MA, et al. Genetic polymorphisms and weight loss in obesity: a randomised trial of hypo-energetic high-versus low-fat diets. PLoS Clin Trials. 2006;1(2):e12. doi:10.1371/journal.petr.0010012

\section{Publish your work in this journal}

Diabetes, Metabolic Syndrome and Obesity: Targets and Therapy is an international, peer-reviewed open-access journal committed to the rapid publication of the latest laboratory and clinical findings in the fields of diabetes, metabolic syndrome and obesity research. Original research, review, case reports, hypothesis formation, expert opinion and commentaries are all considered for publication. The manuscript management system is completely online and includes a very quick and fair peer-review system, which is all easy to use. Visit http://www.dovepress.com/testimonials.php to read real quotes from published authors.

Submit your manuscript here: https://www.dovepress.com/diabetes-metabolic-syndrome-and-obesity-targets-and-therapy-journal 